\title{
Secular and socio-economic trends in compliance with dietary targets in the north Glasgow MONICA population surveys 1986-1995: did social gradients widen?
}

\author{
Wendy Louise Wrieden ${ }^{1, *}$, John Connaghan ${ }^{2}$, Caroline Morrison ${ }^{3}$ and \\ Hugh Tunstall-Pedoe ${ }^{2}$ \\ ${ }^{1}$ Centre for Public Health Nutrition Research, The Institute for Cardiovascular Research, University of Dundee, \\ Ninewells Hospital and Medical School, Dundee DD 1 9SY, UK: ${ }^{2}$ Cardiovascular Epidemiology Unit, The Institute for \\ Cardiovascular Research, University of Dundee, Ninewells Hospital and Medical School, Dundee, UK: ${ }^{3}$ Greater \\ Glasgow Health Board, Glasgow, UK
}

Submitted 4 August 2003: Accepted 4 May 2004

\begin{abstract}
Objective: To compare trends in the consumption of key foods over 10 years in the most deprived and least deprived quarters in north Glasgow, Scotland as defined by the Carstairs deprivation index for their postcode of domicile.

Design: Four random, cross-sectional, age- and gender-stratified population surveys carried out in 1986, 1989, 1992 and 1995. After assigning a deprivation score, foodfrequency questionnaires from 2883 men and 3127 women were examined for compliance with dietary targets, examining trends by gender and within the most and least deprived quarters of the population.

Setting: North Glasgow, Scotland.

Subjects: Over 600 men and 600 women (aged 25-64 years) in each of the four survey years who completed a lifestyle questionnaire including a food frequency section. Results: Increasing trends in the reported consumption of fruit and vegetables and oilrich fish were observed over the 10-year period. However, the trend to increased fruit and vegetable consumption in the most deprived groups was not significant, and in 1995 only $8 \%$ of men and $12 \%$ of women in this group claimed consumption of these foods 4 or more times a day. In general, a higher percentage of those in the least deprived group met the targets for the key foods.

Conclusions: Trends to increasing consumption of fruit and vegetables and fish were in the right direction, but the targets for consumption of certain key foods were met by a minority of the population. The progress towards the target for fruit and vegetables showed widening social gradients with time.
\end{abstract}

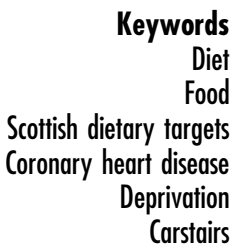

It is easier to make recommendations about what the public should be eating than to measure and monitor over time what is being eaten. The ongoing English and Scottish Health Surveys ${ }^{1,2}$ were introduced in the 1990s to measure lifestyles and coronary risk factors in the general population, but the nutritional information that they record is rather scanty and difficult to relate to nutritional targets. These surveys were preceded, and to some extent inspired, by the Scottish Heart Health Study ${ }^{3}$ and the Scottish MONICA (Monitoring Trends and Determinants in Cardiovascular Disease $)^{4}$ Project surveys, which laboriously incorporated a detailed food-frequency questionnaire (FFQ) modelled on that developed for the Caerphilly Study ${ }^{5}$.

The Scottish Heart Health Study was cross-sectional and conducted in 1984-87. Nutritional analyses are published and have been related to dietary recommendations ${ }^{6}$.
The then Scottish diet was shown to be low in fruit and vegetables and to show a geographical pattern largely related to patterns of social deprivation. Diet was generally poor but worse in men than in women, worse in the west of Scotland, among manual workers, and in smokers. This survey was not repeated as such, although the FFQ was re-administered on one occasion by post.

Contemporaneously with the Scottish Heart Health Study, part of the west of Scotland identified for its very high rates of coronary heart disease mortality, north Glasgow, was chosen for participation in the World Health Organization (WHO) MONICA Project. This monitored coronary disease and risk factors over 10 years. Dietary monitoring, which is difficult and expensive, was not an obligatory component of the WHO MONICA Project. However, the FFQ used in the Scottish Heart Health Study, updated as necessary for specific new items, was 
administered in all four of its independent random population surveys in 1986, 1989, 1992 and 1995. It thus provided a unique source of data on population change in dietary behaviour by age and gender.

North Glasgow, chosen for its high coronary mortality, is not typical of Scotland as a whole. However, it does typify the challenge posed for health promotion and disease prevention in securing change in a post-industrial urban centre. Although professional and managerial groups are under-represented in its social mix, which is biased towards manual occupations and deprivation, there is still a strong social gradient within the population in lifestyles and risk factors and in susceptibility to disease. It is therefore appropriate to examine the recorded dietary changes occurring in the population of north Glasgow over the decade 1986-1995 (during which it had the highest coronary disease rates of 38 WHO MONICA Project populations, but in which these rates began to decline), analysing these changes overall, but also by socio-economic status, against current nutritional recommendations for the population.

Among a number of social indicators that can be used are occupational social class, education and house ownership. Each has some disadvantages, such as how to code long-term unemployment, or lack of gradation. The Carstairs and Morris deprivation index ${ }^{7}$, used here, as updated by McLoone for the 1991 census $^{8}$, is assigned by postcode sector of residence and is derived from four decennial census variables.

During the last decade there has been an increasing tendency for nutrition experts to translate nutritional guidelines and recommendations in terms of foods rather than nutrients. Hence a UK report on diet and cardiovascular disease 9 gave an illustrative example of the average quantities of different foods that would need to be eaten to achieve the nutritional guidelines given in the same report. Similarly, the Scottish Diet report ${ }^{10}$ and the later Scottish Diet Action Plan ${ }^{11}$ set targets for the consumption of certain foods such as fruit and vegetables and bread that would have to be met to achieve the nutrient targets for a healthy diet. The lower limit population goal of $400 \mathrm{~g}$ for fruit and vegetables set by $\mathrm{WHO}^{12}$ was translated into 5-a-day of fruit, vegetables and fruit juice (but not potatoes) and has been discussed by Williams ${ }^{13}$.

It is now established that those from the lower socioeconomic groups continue to have a poorer diet in terms of vitamins and minerals ${ }^{14}$, fruit and vegetable consumption $^{15-17}$ and overall quality ${ }^{6}$. The Scottish Health Survey ${ }^{2}$ also showed that the consumption of healthy foods was more prevalent among informants in social classes I and II than in classes IV and V. However, there are few data on the trends in diet and food consumption in different socioeconomic groups. Although a recent National Food Survey ${ }^{18}$ showed trends in different income groups over the last 50 years, the food groups used cannot be directly related to the targeted foods of the Scottish Diet Action Plan.

It is thus appropriate to look at the trends in food consumption for this north Glasgow population as it represents a group where improvements in diet are urgently required. An FFQ was incorporated into a general health and lifestyle questionnaire and used to monitor the diet at four stages from 1986 to 1995 . Results from the first two dietary surveys of the MONICA study in this area ${ }^{19}$ showed little evidence of improvement in the diet from 1986 to 1989 , but demonstrated the better quality of the diet amongst those who had received further education. In evaluating the dietary information from the four survey years it seemed appropriate to look at and compare the trends in food consumption in quarters according to the Carstairs and Morris deprivation score.

Although there are difficulties implicit in calculating the nutrient intakes of subjects from the FFQ, it is a useful tool to look at habitual intakes of a range of foods (the questionnaire has been subject to several validation studies $^{20-22}$, so the authors are confident that it is a valid tool). It is the observed trends in the consumption of key foods that this paper seeks to address.

\section{Methods}

\section{Subjects}

The sample comprised those who participated in the MONICA risk factor surveys and completed the food frequency and lifestyle questionnaires. Surveys were carried out in 1986, 1989, 1992 and 1995 using a twostage sampling method. In each year, a random sample of 30 general practitioners (GPs) was selected from the list of GPs $(\sim 200)$ in north Glasgow. From this a random sample of men and women aged 25-64 years was chosen, stratified by gender and 10-year age group. The target was 200 in each age-gender group. These individuals were sent a questionnaire and an invitation to attend a clinic for examination.

Subjects attended the screening clinic and gave consent to a range of measurements. The personal health record, which contained sections on personal details, medical history, a smoking questionnaire and an $\mathrm{FFQ}^{20,22,23}$, was checked by the clinic nurse.

\section{Analysis}

The percentage of men and women, those in the different age groups, non-smokers (including ex-smokers) and current smokers, and those in the Carstairs deprivation categories (DEPCAT) were calculated for each of the survey years.

The FFQ asked subjects about weekly (number of days each week, once a month, rarely or never) consumption of over 65 different foods and drinks. The percentage of subjects eating a food was calculated for all of the foods for which a consistent definition had been maintained over 
the four surveys. Foods such as shellfish, tomatoes, and various snack and confectionery items were excluded, as these were additions to the 1992 and 1995 FFQs. Where foods were grouped to give a total consumption frequency for a group such as fruit and vegetables or breakfast cereals, weekly frequencies were added (using 0.5 for the 'less than once a week but at least monthly' category) together. In addition to frequency of bread consumption, subjects were asked what type of bread they ate (white, brown, wholemeal, rolls) and also to specify the size of slice or roll (thick, medium or thin for slice) eaten for the different types. To calculate weight of bread eaten, the frequency of consumption was multiplied by a standard portion weight for the size. To compare intakes with national targets, a frequency equivalent to the target frequency was assigned (Table 1). The target of 4 or more times a day for fruit and vegetables takes into account that the range of these foods is limited in the FFQ and probably underestimates the true amount. The target of $154 \mathrm{~g}$ of bread daily with $50 \%$ or more from wholemeal or brown bread was devised to complement the dietary target of increasing bread consumption (from 106 to $154 \mathrm{~g}$ ) mainly using wholemeal and brown breads ${ }^{11}$. Proportions were compared using the chi-square test with a test for linearby-linear association. The percentages of subjects achieving the targets are presented after standardising for age.

Socio-economic group was derived for the postcode using the Carstairs and Morris deprivation score $^{7}$ as updated by McLoone ${ }^{8}$ using 1991 census data. In this study the postcodes were ranked in the order of the score. The population aged 25-64 years for each postcode sector was obtained from the small area statistics from the 1991 census, and the total study population was divided into quarters (socio-economic quarters) according to the updated Carstairs and Morris score rankings (Q1 is the least deprived quarter and Q4 the most deprived). These quarters were directly calculated from the continuous Carstairs scores rather than the seven Carstairs categories (which divide the Scottish population into seven groups of similar number ${ }^{8}$ ) and have been used in a previous study as an effective divisor for socio-economic group ${ }^{24}$. The percentage of men and women meeting the targets in Q1 and Q4 are presented for each survey year and for all years. Logistic regression was used to test for trends over time and to test for any difference in trends between Q1 and Q4. Exclusion of implausible results was carried out by converting the food frequency data to give an estimate of energy intake ${ }^{5,19}$ and discounting those questionnaires that gave energy intake of $<2.5 \mathrm{MJ}$ or $>25 \mathrm{MJ}$.

\section{Results}

In total, 2883 men and 3127 women completed lifestyle and food-frequency questionnaires across the four survey years but within this number not all questionnaires were valid for every question due to some omissions. The exclusion criteria of $<2.5 \mathrm{MJ}$ and $>25 \mathrm{MJ}$ resulted in a loss of $6 \%$ of questionnaires, but the results obtained were similar with and without the exclusion. Table 2 gives the results after the exclusion criteria were applied.

There were similar percentages of men and women in each of the four survey years. The proportion of nonsmokers was slightly higher in the more recent surveys and among women. Approximately $40 \%$ of the sample was classified into the most deprived DEPCAT score, 7. The most deprived quarter of the Glasgow MONICA population comprised $55 \%$ of those in DEPCAT 7, while the least deprived quarter contained those from DEPCAT 2, 3 and 4 and about a quarter of those in DEPCAT 5.

Table 3 shows the percentage of men and women achieving the target consumption of the key foods for each of the survey years. Significant linear-by-linear associations were seen for total fruit and vegetables and oil-rich fish, indicating a trend to increase with the year of survey. Almost half the women in 1995 claimed consumption of oil-rich fish but only $42 \%$ of men. In all years a higher percentage of women than men met the target for fruit and vegetables (20\% vs. $12 \%$ in 1995 ).

When the most deprived and least deprived quarters were compared, the 'all years' frequency (see Fig. 1) showed a higher proportion of subjects in the least deprived quarter consuming bread with at least 50\% wholemeal or brown bread, total fruit and vegetables, breakfast cereals, and oil-rich fish (women only). The percentage of men and women consuming the target for bread consumption was less than $5 \%$ in the most deprived quartile.

Closer examination of the trends in food consumption showed that the overall trends were not seen in certain groups (Fig. 1). For combined fruit and vegetable

Table 1 Food/food groups for which targets are set for the year 2005 and equivalent frequencies from the food-frequency questionnaire

\begin{tabular}{|c|c|c|}
\hline Food group & Scottish Diet Action Target & Target frequency of consumption \\
\hline $\begin{array}{l}\text { Breakfast cereals } \\
\text { Bread } \\
\text { Fruit and vegetables } \\
\text { Oily fish }\end{array}$ & $\begin{array}{l}34 \mathrm{~g} \mathrm{day}^{-1} \\
154 \mathrm{~g} \mathrm{day}^{-1} \text { mainly from wholemeal or brown } \\
>400 \mathrm{~g} \mathrm{day}^{-1} \\
88 \mathrm{~g} \mathrm{week}^{-1}\end{array}$ & $\begin{array}{l}\geq 6 \text { times a week } \\
\geq 154 \mathrm{~g} \text { daily }(\geq 50 \% \text { wholemeal or brown })^{*} \\
\geq 4 \text { times a day, i.e. } 28 \text { times per week } \dagger \\
\text { once a week }\end{array}$ \\
\hline
\end{tabular}

* Calculated using type of bread and average portion sizes for thick, medium and thin sliced bread.

† Four times a day was used rather than five to allow for fact that the range of fruits and vegetables was limited in the food-frequency questionnaire and probably underestimates the true amount. 
Table 2 Number (percentage of subjects $\dagger$ ) in each survey by gender, smoking habit and Carstairs deprivation score (DEPCAT)

\begin{tabular}{|c|c|c|c|c|c|}
\hline \multirow[b]{2}{*}{ Grouping } & \multirow[b]{2}{*}{ 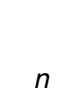 } & \multicolumn{4}{|c|}{ Year of survey } \\
\hline & & 1986 & 1989 & 1992 & 1995 \\
\hline All & 5624 & 1246 & 1377 & 1297 & 1704 \\
\hline $\begin{array}{l}\text { By gender } \\
\text { Men } \\
\text { Women }\end{array}$ & $\begin{array}{l}2694 \\
2930\end{array}$ & $\begin{array}{l}645(52) \\
601(48)\end{array}$ & $\begin{array}{l}645(47) \\
732(53)\end{array}$ & & $\begin{array}{l}794(47) \\
910(53)\end{array}$ \\
\hline $\begin{array}{l}\text { By gender/smokin } \\
\text { Men }\end{array}$ & ng hab & & & & \\
\hline $\begin{array}{l}\text { Smokers } \\
\text { Non-smokers }\end{array}$ & $\begin{array}{l}1462 \\
1364\end{array}$ & & & & \\
\hline $\begin{array}{l}\text { Women } \\
\text { Smokers } \\
\text { Non-smokers }\end{array}$ & & & & & \\
\hline $\begin{array}{l}\text { By DEPCAT } \\
\text { Men }\end{array}$ & & & & & \\
\hline $\begin{array}{l}\text { Least deprived } \\
\text { DEPCAT } 2 \\
\text { DEPCAT } 3 \\
\text { DEPCAT } 4 \\
\text { DEPCAT } 5 \\
\text { DEPCAT } 6 \\
\text { Most deprived }\end{array}$ & $\begin{array}{r}9 \\
131 \\
82 \\
435 \\
214 \\
705 \\
1118\end{array}$ & $\begin{array}{c}2(<1) \\
20(3) \\
30(5) \\
94(15) \\
52(8) \\
144(22) \\
300(47)\end{array}$ & $\begin{array}{c}6(1) \\
37(6) \\
8(1) \\
142(22) \\
58(9) \\
155(24) \\
239(37)\end{array}$ & $\begin{array}{c}1(<1) \\
40(7) \\
12(2) \\
69(11) \\
43(7) \\
180(30) \\
265(43)\end{array}$ & $\begin{array}{c}0 \\
34(4) \\
32(4) \\
127(16) \\
61(8) \\
226(28) \\
314(40)\end{array}$ \\
\hline & & & & & \\
\hline $\begin{array}{l}\text { Least deprived } \\
\text { DEPCAT } 2 \\
\text { DEPCAT } 3 \\
\text { DEPCAT } 4 \\
\text { DEPCAT } 5 \\
\text { DEPCAT } 6 \\
\text { Most deprived }\end{array}$ & $\begin{array}{r}10 \\
143 \\
93 \\
451 \\
256 \\
748 \\
1226\end{array}$ & $\begin{array}{c}4(1) \\
21(4) \\
27(5) \\
90(15) \\
34(6) \\
123(21) \\
300(50)\end{array}$ & $\begin{array}{r}6(1) \\
36(5) \\
5(1) \\
127(17) \\
87(12) \\
184(25) \\
286(39)\end{array}$ & $\begin{array}{c}0 \\
38(6) \\
18(3) \\
89(13) \\
45(7) \\
194(28) \\
303(44)\end{array}$ & $\begin{array}{c}0 \\
48(5) \\
43(5) \\
145(16) \\
90(10) \\
247(27) \\
337(37)\end{array}$ \\
\hline
\end{tabular}

†Percentages were rounded to whole numbers and may not always add up to $100 \%$.

consumption, the most deprived quarter showed no trend to increasing consumption such that, in 1995, 17\% of men and $29 \%$ of women in the least deprived but only $8 \%$ of men and $12 \%$ of women in the most deprived quarter met the Scottish Diet Action Plan target. In 1986 only $6-10 \%$ of people met the target, but there were no significant differences between the least and most deprived groups.

\section{Discussion}

The population of north Glasgow represents the 'worsecase scenario' for Scotland given what is already known about diet, deprivation and disease. Smoking is another risk factor in the development of cardiovascular disease and the percentage of smokers in the sample, although showing a trend to decrease, was still higher (over 40\%) than in the general Scottish population $(35 \%)^{2,25}$ in 1995. Micronutrient intakes and fruit and vegetable intakes are known to be lower in smokers ${ }^{26,27}$ compared with non-smokers, but the percentage of smokers is also known to be higher in those from a more deprived background ${ }^{2}$. However, standardisation for smoking did not eliminate the effect of social status on the results presented here, so results are presented age-standardised only.

The Scottish Health Survey of $1998^{2}$ reported that $60 \%$ of adults in social class I ate fruit once or more per day, compared with only $34 \%$ of adults in social class V. In social class I, $82 \%$ ate oil-rich fish more than once a month compared with $52 \%$ in social class $\mathrm{V}$. Wholemeal bread consumption decreased from 21 to $6 \%$ from social class I to V. Similar differences are seen in the successive National Food Surveys when comparing the higher- with the lowerincome groups ${ }^{28,29}$. Anderson and Hunt ${ }^{30}$ classified a community sample of people in their mid-30s from the Glasgow area into 'healthy' and 'less healthy' eaters. They found a significantly higher proportion of healthy eaters amongst women, non-manual workers, those with an income greater than $\$ 160$ per week, those who left school with qualifications and those who owned their houses. The Carstairs deprivation index is based on postcode areas defined by male unemployment, car ownership, overcrowding and low social class, factors which are undoubtedly linked with low income, educational attainment and poor housing. Although the percentage of subjects from the least deprived and most deprived deprivation category may vary slightly from year to year (Table 2), the method of using least deprived and most

Table 3 Percentage of men and women achieving targets in MONICA (Monitoring Trends and Determinants in Cardiovascular Disease) survey years (age-standardised)

\begin{tabular}{|c|c|c|c|c|c|c|}
\hline \multirow[b]{2}{*}{ Food } & \multirow{2}{*}{$\begin{array}{c}\text { Target frequency } \\
\text { (weekly except bread) }\end{array}$} & \multicolumn{5}{|c|}{$\%$ of subjects } \\
\hline & & 1986 & 1989 & 1992 & 1995 & All \\
\hline \multicolumn{7}{|l|}{ Men } \\
\hline Total fruit and vegetables & 28 or more & 7 & 7 & 11 & $12^{\star \star \star}$ & 9 \\
\hline Wholemeal + brown bread $\geq 50 \%$ of bread eaten & $\geq 154 \mathrm{~g}$ daily & 7 & 9 & 10 & 9 & 9 \\
\hline Total breakfast cereals & 6 or more & 24 & 27 & 27 & $29^{\star *}$ & 28 \\
\hline Oil-rich fish & once or more & 29 & 33 & 43 & $41^{\star \star \star}$ & 38 \\
\hline \multicolumn{7}{|l|}{ Women } \\
\hline Total fruit and vegetables & 28 or more & 10 & 15 & 16 & $20^{\star \star \star}$ & 16 \\
\hline Wholemeal + brown bread $\geq 50 \%$ of bread eaten & $\geq 154 \mathrm{~g}$ daily & 8 & 6 & 8 & $9^{*}$ & 8 \\
\hline Total breakfast cereals & 6 or more & 27 & 30 & 30 & $32^{\star \star}$ & 30 \\
\hline Oil-rich fish & once or more & 33 & 42 & 51 & $47^{\star \star \star}$ & 44 \\
\hline
\end{tabular}

Significant trend: ${ }^{\star \star *}, P<0.001 ;{ }^{* *}, P<0.01 ;{ }^{*}, P<0.05$. 

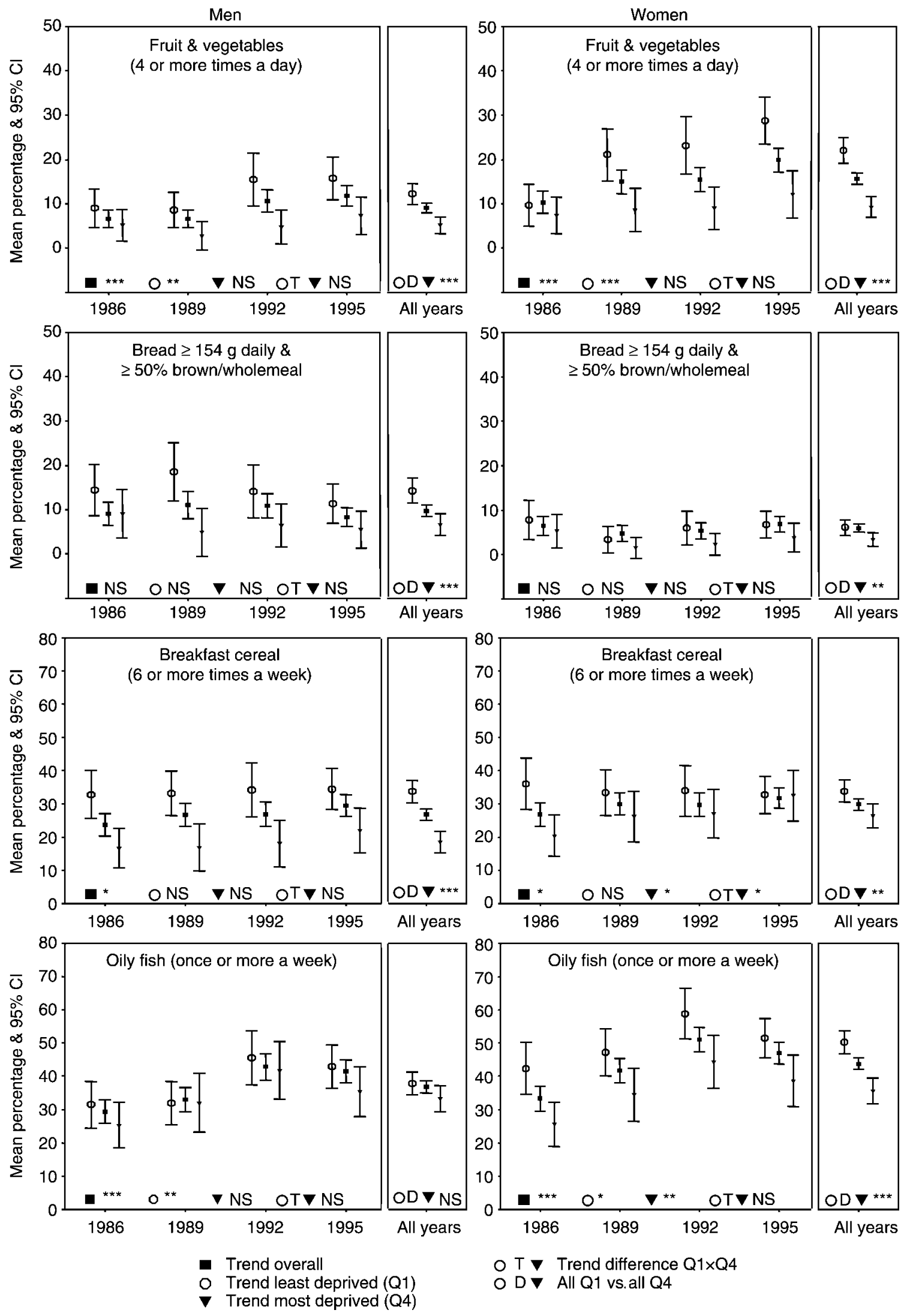

Fig. 1 Mean percentage (and 95\% confidence interval $(\mathrm{Cl})$ ) of men and women consuming action targets: comparison of least deprived and most deprived quarters. Trends over time and differences between Carstairs quarters calculated using logistic regression: NS, not significant; ${ }^{*}, P<0.05 ;{ }^{\star *}, P<0.01 ;{ }^{* * *}, P<0.001$ 
deprived quarters as opposed to the actual DEPCAT scores means that equal proportions can be compared across the years. These quarters have been derived from continuous Carstairs scores rather than the actual DEPCAT scores. Using this measure of social deprivation the data presented in this paper show that the dietary differences seen in the general population are seen in a sample which is skewed towards the lower end of the deprivation scale.

There has been little work looking at trends towards dietary or food targets, although some authors have compared results from cross-sectional studies with targets. For example, Bolton-Smith ${ }^{6}$ compared the diets of the middle-aged men and women in the Scottish Heart Health Survey with the $\mathrm{WHO}^{12}$ recommendations for fruit and vegetables ( $400 \mathrm{~g} \mathrm{day}^{-1}$ ) and found that only $7.9 \%$ of nonmanual and $4.9 \%$ of manual women and $4.8 \%$ of nonmanual and $3.2 \%$ of manual men met the target. The MONICA survey data presented here for the same year (1986) show little difference between the least deprived men and women (9.0 and 9.7\%), and although the most deprived men and women had lower percentages (5.8 and $7.4 \%$, respectively) meeting the target, the differences were not significant. However, in subsequent years the differences were significant, emphasising the increase in the percentage of the least deprived meeting the targets but little change in the most deprived. Despite this there was no significant difference in trends (Fig. 1) using a logistic regression test, but this should not distract from the fact that there were obvious differences in fruit and vegetable consumption in 1995 that were not apparent in 1986. This perhaps shows that health promotion messages are being taken up and put into practice by the least deprived sector but not by the most deprived. In 1995, 29\% of the least deprived women claimed consumption of 4 or more portions of fruit and vegetables per day compared with only $12 \%$ of the most deprived women studied.

The characteristics of those complying with the $400 \mathrm{~g}$ day $^{-1}$ guideline have been studied ${ }^{16}$ using data from the Dietary and Nutritional Survey of British Adults ${ }^{14}$ carried out in 1986-1987. In general, a considerably higher number of compliers (approximately 40\%) was found in the overall UK sample than in the north Glasgow sample, but the former used weighed intakes rather than an FFQ and was thus more able to quantify the amounts and types of foods eaten. However, they did note the fact that only one-third of those sampled in the north of England and Scotland were compliers and that the compliers were more likely to be in the non-manual social classes. Higher consumption of wholemeal breads, high-fibre cereals and fish/shellfish was seen amongst the compliers, suggesting the trend seen here to increase fruit and vegetable consumption might go hand in hand with a trend to increase these other foods for which targets have been set. However, the information presented in Table 3 and Fig. 1 shows no trend to increase breakfast cereals or brown/ wholemeal bread although the socio-economic differences are apparent. Nevertheless, given the increase in fruit and vegetable consumption that has occurred in more affluent sectors of society, it is possible with an increased focus on the promotion of bread and cereal consumption that a similar increase in these foods could be brought about. It must not be forgotten that there is a history of mixed messages about these foods and they are still perceived as fattening by some or cheap and filling by others. There is likely to be more resistance to increasing these foods in the diet and innovative ways are needed to increase both these and fruit and vegetables, particularly in the diets of the most vulnerable in Scotland.

A trend to increasing consumption of oily fish was seen in both the least and most deprived quarters, with an overall change from around 30\% in 1986 to $42-47 \%$ eating this food once a week in 1995 . However, it is likely that this increase is mainly due to the consumption of canned tuna. This may be preferable to consumption of other more fatty protein sources but is unlikely to provide the beneficial effects of $n-3$ fatty acids as these are considerably depleted in canned tuna compared with other oily fish ${ }^{31}$.

The comparison of the percentage of men and women meeting the Scottish Diet Action targets for fruit and vegetables, bread and breakfast cereals and oily fish confirmed previous reports that the least deprived are more likely to achieve the targets. Over the 10-year period of the MONICA population surveys in north Glasgow a trend to increasing consumption of fruit and vegetables and oily fish was seen, but the percentage meeting targets for breakfast cereal and wholemeal/brown bread consumption showed little change. There was evidence that fruit and vegetable consumption remained static in the most deprived quarter, the group where coronary events are approximately twofold higher than in the least deprived group ${ }^{24}$. This is despite the fact that the Goodhearted Glasgow project was started about this time. This was a heart disease prevention intervention that targeted men and women in Glasgow aged 20-60 years and ran from 1985 to the early nineties. Over 60000 people participated. All were offered the Beating Heart Disease booklet (developed by the Health Education Authority and supported by the Health Education Board for Scotland (HEBS)) that contained healthy eating information. They also received other nutritional leaflets developed by HEBS. Cholesterol was measured in all participants except for the few who refused consent. They were given a diet sheet, the content of which depended on their cholesterol level.

Thus the need to find mechanisms to improve the diet in areas of deprivation should still be a priority. The reasons for poor diet are multi-factorial and may include limited access to affordable food items, and limited disposable income, cooking facilities and cooking skills, combined with family preferences and misconceptions about current dietary guidelines. A study by the low-income project group has shown that income support payments are not 
enough to cover a basic healthy $\operatorname{diet}^{32}$. In addition, a number of studies ${ }^{33}$ suggest that, as well as personal social disadvantage (e.g. socio-economic status), poor neighbourhoods provide fewer opportunities for healthpromoting activities than more affluent communities. They also imply that changes in health behaviours can be facilitated by health-promoting activities at community level such as interventions to improve food skills.

The Scottish Diet Action Plan dietary targets, reinforced in the document Towards a Healthier Scotland ${ }^{34}$, are for the year 2005. It is publicly acknowledged that: 'Next to smoking, our diet is the single and most significant cause of our poor health, contributing to a range of serious illnesses, which includes coronary heart disease, certain cancers, strokes osteoporosis and diabetes. The poor diet of deprived communities is a major reason why they experience such poor health' (pp. 20-21).

The findings of this study suggest that these targets are unlikely to be met by 2005 . Progress on the implementation of the Action Plan and nutritional guidelines has been slow to date, but with the formation of the Food Standards Agency and appointment of a Scottish Food and Health Coordinator, it is hoped that faster progress will be made.

The recently published policy document Improving Health in Scotland - The Challenge ${ }^{35}$ continues to support implementation of the Scottish Diet Action Plan and sets a strategic plan to do so. An integrated programme of communication and public education was launched in January 2003, following the appointment of a food and health co-ordinator. An Expert Panel on School Meals has recently completed its work to provide guidelines on the provision and presentation of school meals ${ }^{36}$, and recommendations to monitor food consumption between 2003 and 2010 are in place.

\section{Acknowledgements}

The Scottish MONICA project was funded by grants from the Chief Scientist Office of the Scottish Executive Department of Health and the British Heart Foundation.

The views expressed in this paper are those of the authors and do not necessarily reflect those of the funding body.

\section{References}

1 Department of Health. Health Survey for England 2000. London: The Stationery Office, 2001.

2 The Scottish Executive Health Department. The Scottish Health Survey 1998, Vol. 1. Edinburgh: The Stationery Office, 2000.

3 Smith WC, Crombie IK, Tavendale R, Irving JM, Kenicer MB, Tunstall-Pedoe H. The Scottish Heart Health Study: objectives and development of methods. Health Bulletin 1987; 45(4): 211-7.

4 Tunstall-Pedoe H. MONICA Monograph and Multimedia Sourcebook. Geneva: World Health Organization, 2003.
5 Yarnell JWG, Fehily AM, Milbank JE, Sweetnam PM, Walker CL. A short dietary questionnaire for use in an epidemiological survey: comparison with weighed dietary records. Human Nutrition: Applied Nutrition 1983; 37A: 103-12.

6 Bolton-Smith C. The Chief Scientist reports... The diets of Scottish men and women in relation to nutritional recommendations for health. Health Bulletin 1991; 49(5): $264-71$.

7 Carstairs V, Morris R. Deprivation and Health in Scotland. Aberdeen: Aberdeen University Press, 1991.

8 McLoone P. Carstairs Scores for Scottish Postcode Sectors from the 1991 Census. Glasgow: Public Health Research Unit, 1994.

9 Department of Health. Nutritional Aspects of Cardiovascular Disease. Report on Health and Social Subjects No. 46. London: HMSO, 1994.

10 The Scottish Office, Home and Health Department. The Scottish Diet: Report of a Working Party to the Chief Medical Officer for Scotland. Edinburgh: HMSO, 1993.

11 The Scottish Office, Department of Health. Scotland's Health. A Challenge to Us All. Eating for Health: A Diet Action Plan for Scotland. Edinburgh: HMSO, 1996.

12 World Health Organization (WHO). Diet, Nutrition, and the Prevention of Chronic Diseases. Technical Report Series No. 797. Geneva: WHO, 1990.

13 Williams C. Healthy eating: clarifying advice about fruit and vegetables. British Medical Journal 1995; 310: 1453-5.

14 Gregory J, Foster K, Tyler H, Wiseman M. The Dietary and Nutritional Survey of British Adults. London: HMSO, 1990.

15 Wrieden WL, Bolton-Smith C, Brown CA, Tunstall-Pedoe H. Fruit and vegetable consumption in north Glasgow: some results from the MONICA study of 1986 and 1989. Proceedings of the Nutrition Society 1993; 52: 12A.

16 Hunt CJ, Nichols RN, Pryer JA. Who complied with national fruit and vegetable population goals - findings from the dietary and nutritional survey of British adults. European Journal of Public Heath 2000; 10(3): 178-84.

17 Henderson L, Gregory J, Swan G. The National Diet and Nutrition Survey: Adults aged 19-64 years. Vol. 1. Types and Quantities of Foods Consumed. London: The Stationery Office, 2002.

18 Department for Environment Food and Rural Affairs. National Food Survey 2000: Annual Report on Food Expenditure, Consumption and Nutrient Intakes. London: The Stationery Office, 2001.

19 Wrieden WL, Bolton-Smith C, Brown CA, Tunstall-Pedoe H. Nutrient intakes in North Glasgow: results from the Scottish MONICA studies of 1986 and 1989. Journal of Human Nutrition and Dietetics 1994; 7: 199-207.

20 Bolton-Smith C, Casey CE, Gey KF, Smith WCS, TunstallPedoe H. Antioxidant vitamin intakes assessed using a foodfrequency questionnaire: correlation with biochemical status in smokers and non-smokers. British Journal of Nutrition 1991; 65: 337-46.

21 Bolton-Smith CM, Milne AC. Food frequency versus weighed intake data in Scottish men. Proceedings of the Nutrition Society 1991; 50: 35A.

22 Bolton-Smith C, Smith WCS, Woodward M, Tunstall-Pedoe $\mathrm{H}$. Nutrient intakes of different social-class groups: results from the Scottish Heart Health Study (SHHS). British Journal of Nutrition 1991; 65: 321-35.

23 Bolton-Smith C, Brown CA, Tunstall-Pedoe H. Nutrient sources in non-manual and manual occupational group. Results from the Scottish Heart Health Study (SHHS). Journal of Human Nutrition and Dietetics 1991; 4: 291-306.

24 Morrison C, Woodward M, Leslie W, Tunstall-Pedoe H. Effect of socioeconomic group on incidence of, management of, and survival after myocardial infarction and coronary death: analysis of community coronary event register. British Medical Journal 1997; 314(7080): 541-6. 
25 Joint Health Surveys Unit. Scottish Health Surveys 1995, Vol. 1. Edinburgh: The Stationery Office, 1997.

26 Bolton-Smith C. Antioxidant vitamin intakes in Scottish smokers and nonsmokers. Annals of the New York Academy of Sciences 1993; 686: 347-60.

27 Margetts BM, Jackson AA. Interactions between people's diet and their smoking habits: the dietary and nutritional survey of British adults. British Medical Journal 1993; 307(6916): 1381-4.

28 Ministry of Agriculture, Fisheries and Food. National Food Survey 1997. London: The Stationery Office, 1998.

29 Ministry of Agriculture, Fisheries and Food. National Food Survey 1994. London: HMSO, 1995.

30 Anderson AS, Hunt K. Who are the 'healthy eaters'? Eating patterns and health promotion in the west of Scotland. Health Education Journal 1992; 51(1): 3-10.

31 Ministry of Agriculture, Fisheries and Food (MAFF). Fatty Acids. Seventh Supplement to the McCance \& Widdowson's
The Composition of Foods, 5th ed. London: Royal Society of Chemistry/MAFF, 1998.

32 Nelson M, Oldfield N, Dallison J, Hutton S, Paterakis S, Sutherland $\mathrm{H}$, et al. Low Cost but Acceptable - A Minimum Income Standard for the UK: Families with Young Children. Bristol: The Policy Press and the Zacheus 2000 Trust, 1998.

33 McGlone P, Dobson B, Dowler E, Nelson M. Food Projects and How They Work. York: Joseph Rowntree Foundation, 1999.

34 The Scottish Office, Department of Health. Towards a Healthier Scotland. Edinburgh: The Stationery Office, 1999.

35 Scottish Executive. Improving Health in Scotland - The Challenge. Edinburgh: The Stationery Office, 2003.

36 Scottish Executive. Hungry for Success: A Whole School Approach to School Meals in Scotland. Final Report of the Expert Panels on School Meals. Edinburgh: The Stationery Office, 2003. 